\title{
Perspectivas de la historia judía de la Corona de Aragón *
}

\author{
DAvid Romano **
}

\section{INTRODUCCIÓN}

Tratar de perspectivas presupone implícitamente, o explícitamente, hablar de las cosas hechas, de la situación, es decir, presentar un estado de la cuestión, a partir del cual la investigación puede o debe avanzar. Eso significa que, aunque no se quiera, se recuerdan cosas dichas en ocasiones anteriores ${ }^{1}$, aunque aquí se expongan en un contexto más amplio. Para hacerlo así hay dos razones básicas: la primera es evitar que alguien alegue ignorancia, o sea, que nadie pueda decir que no se enteró; la segunda es abrir horizontes para discutir, para rebatir si es preciso, entablar diálogo que desemboque en ese avance al que fugazmente he aludido. Para mí, esto último es muy importante, lo más importante de la ponencia de un congreso: una ponencia ha de enfocar una temática amplia, en cuya discusión se cuenta con la participación de muchas personas que habitualmente no suelen reunirse, o no pueden hacerlo.

Si pasamos más allá de la teorización, y nos concentramos en la historia de los judíos, y más en concreto en la historia judía hispánica ${ }^{2}$, hay

* En la realización de este trabajo me he beneficiado parcialmente de la ayuda de los proyectos n. ${ }^{\text {os }}$ PB87-0011-C02-01 y PB90-0449-C02-1 de la DGICYT.

** Universidad de Barcelona.

Además de lo publicado en ROMANO, David, «La històra dels jueus a Catalunya problemàtica i perspectives», Revista de Catalunya. (Barcelona), nova etapa, 3 (1986), 60-72, me refiero a mi conferencia acerca de Los judíos hispánicos entre tolerancia y marginación (Sigüenza 1.7.1991), así como a mis ponencias sobre Rasgos de la minoria judia en la Corona de Aragón (Ribadavia 14-17.10.1991, congreso sobre «Judíos y conversos en la historia») y Judios hispánicos: coexistencia, tolerancia, marginación (1391-1492: de los alborotos a la expulsión) (Sevilla 25.11-30.11.1991, congreso III Jornadas hispano-portuguesas de Historia Medieval, sesión I: «El final de la convivencia: judíos y conversos en la Península lbérica al final de la Edad Media).

Sobre el sentido de lo hispánico y la relegación del para entonces anacrónico "español» he hablado varias veces, las últimas en los congresos de Ribadavia y Sevilla citados en la nota anterior. 
que indicar que demasiado a menudo esta historia es un subproducto, con la natural salvedad de que también hay excepciones, los raros casos a los que de vez en vez me referiré.

Cuestión importante consiste en señalar o, simplemente, recordar que una buena historia hispanojudía debe hacerse sumando y contrastando materiales judíos y no judíos, lo que significa usar a la vez fuentes en hebreo, latín y romance(s), aunque la riqueza «cuantitativa» procede de las no judías, lo que invalida la opinión de algún autor ${ }^{3}$ contrario a su validez.

He vacilado mucho acerca de cuál es el mejor camino para adentrarse en esa historia, si partir de lo hebreo o de lo no hebreo. Ahora pienso que depende de las circunstancias. Aunque la preparación sin duda es difícil, resulta palmario que lo óptimo es conocer y valerse de lo uno y de lo otro, tal como hice en una ocasión ${ }^{4}$, he empezado a hacer en otra ${ }^{5}$, y como últimamente está trabajando Assis ${ }^{6}$.

Bastantes de las afirmaciones o sugerencias que haré son aplicables a otras naciones hispánicas. Pero muchos autores confunden o engloban en un todo homogéneo lo que de por sí es heterogéneo. Hablan en general de todas las naciones hispánicas a la vez, narrando hechos que frecuentemente se conocen gracias a la Corona de Aragón: es el caso de Neuman ${ }^{7}$, que sin embargo es obra menos conocida de lo que debiera ser. La Corona de Aragón es y puede servir de modelo para las demás naciones hispánicas. No parece necesario explicar aquí qué es la Corona de Aragón ${ }^{8}$, pero quizás sí recordar brevemente que era un conglomerado

3 RIVKIN, Ellis, «The utilization of non-jewish sources for the reconstruction of Jewish history", The Jewish Quarterly Review. (Philadelphi a), XLVIII, 1957-1958, (págs.), 183-203.

4 Romano, David, "Responsa y repertorios documentales (Nuevos detalles sobre el caso de Vidalón de Porta)», Sefarad (Madrid-Barcelona), XXVI, (9) 1966 47-52, reimpreso en Romano, David, De historia judia hispánica. (Barcelona, Universitat de Barcelona, 1991), 131-136.

5 Me refiero a un estudio acerca de miembros de la familia Surí, a base de documentos del Archivo de la Corona de Aragón y de los responsa de Ribaš.

- Véase, por ejemplo, Assis, Yom Tov, Los judíos de Cataluña: fuentes y posibilidades de estudio, ponencia presentada En «' Col.loqui d'hiustòria dels jueus a la Corona d'Aragó" (Institut d'Estudis Ilerdencs, Lleida 1991), 139-155. Y un ejemplo concreto en el artículo que citaré más adelante (nota 101). En este congreso él mismo lo explicará, sin duda mucho mejor que yo.

Neuman, Abraham A., The Jews in Spair. Their social, political and cultural life during the Middle Ages. The Jewish Publication Society of America. Philadelphia 1942. 2 vols. Existen muchas reimpresiones.

Para un primer conocimiento de esa obra, puede leerse la recensión de Francisco Cantera publicada en Sefarad. (Madrid-Barcelona), IV (1944), 399-416.

${ }^{3}$ Lo he hecho con algún detalle en el $\$ 0.1$ (Unidad y diversidad de la Corona de Aragón) de mi ponencia Rasgos de la minoría judía en la Corona de Aragón, presentada en el congreso celebrado en Ribadavia (que he citado en la nota 1). 
de estados ${ }^{9}$, que formaban una nación unificada sólo por el hecho de tener un soberano común. Y si hablo de la Corona de Aragón como modelo o guía metodológica no lo hago sólo porque yo viva allí, sino por la cantidad y calidad de la documentación conservada.

El origen remoto de esta ponencia son mis largos años de búsqueda archivística plasmada en publicaciones analíticas. A continuación vino una etapa de exposiciones sintéticas, que abrirán paso a investigaciones futuras: éste es el origen próximo de lo que voy a exponer.

\section{PERIODIZACIÓN ${ }^{10}$}

Desde el año 876 hasta su expulsión generalizada en 1492, con mayor o menor frecuencia la presencia de judíos está documentada prácticamente en todas las localidades de la Corona de Aragón: viven en las juderías, de localización conocida; incluso se sabe la situación de algunos cementerios y se conservan los restos humanos del de Barcelona, restos que demuestran que los judíos no se distinguían físicamente de los cristianos. Los núcleos más grandes estaban organizados en las llamadas aljamas de judíos.

Para la historia externa de la Corona de Aragón han de tenerse en cuenta unas fechas. Se trata de fechas que citaré ahora en orden cronológico inverso.

La expulsión de los judíos en el año 1492 (para el Rosellón en 1493), fecha que también es válida para la Corona de Castilla, pero no para los reinos de Navarra ni de Portugal. Es un hecho general, pero presenta ligeros matices cronológicos.

Otro suceso había acontecido un siglo antes, en el año 1391, cuando hubo alborotos antijudíos en la Corona de Castilla y en la Corona de Aragón (excepto en la ciudad de Zaragoza y en algunas poblaciones del reino de Aragón), pero nada pasó ni en Navarra ni en Portugal.

Otro siglo antes, en los años 1283 y 1284 en los diferentes estados de la Corona de Aragón se dictaron leyes restrictivas para las actividades

9 Hablo de "estados», que en conjunto formaban la «nación» que solemos llamar Corona de Aragón. Dejando de lado toda actitud política o ideológica actual, yo uso esta nomenclatura: «nación» integrada por «estados".

${ }^{10}$ Sigo muy de cerca las ideas expuestas en Die jüdische Geschichte in den Staaten der Krone von Aragón. - En «Sepharadim-Spaniiolen. Die Juden in Spanien bis 1492-Die sepahardische Diasporas (Studia Judaica Austriaca [Wien], XIII (1992), 23-44. 
de los judíos, concretadas en la decisión de que no pudieran ocupar cargos públicos. Se trata de leyes que no tuvieron paralelo ni en la Corona de Castilla ni en Navarra ni en Portugal.

Antes de estos tres hechos, o sea, dos sucesos y unas leyes, para nuestro tema no hay más fechas de significado especial sino un hito puramente documental: hacia el año 1252 se organiza la cancillería de la Corona de Aragón; pero es evidente que se trata de algo ocasional aunque con consecuencias históricas. Por eso voy a la busca de un momento señalado que pueda servirme para establecer una división. Por ahora sólo lo veo en el año 1213, en que se inicia el reinado de Jaime I; pero pienso también en que por entonces, exactamente en 1215, el Concilio IV de Letrán dictó unos cánones que orientaron decisivamente la actitud cristiana hacia los judíos.

A base de estas fechas quedan delimitados cuatro períodos: $\left.1 .^{\circ}\right)$ hasta $\left.\left.\left.1213 ; 2 .^{\circ}\right) 1213-1283 ; 3 .^{\circ}\right) 1284-1391 ; 4 .^{\circ}\right) 1391-1492$. En la presente ocasión tan sólo me referiré a los tres últimos períodos, es decir, a lo que suele Ilamarse Baja Edad Media: la escasez documental hace muy difícil ahondar en el conocimiento de épocas anteriores.

\section{LAS FUENTES Y SUS POSIBILIDADES ${ }^{11}$}

\subsection{Preliminares}

Quizás algún día convendrá abordar especialmente de una manera sistemática la cuestión de las fuentes, sobre todo de las fuentes escritas. Pero ahora, después de exponer algunas consideraciones de carácter general, me limitaré a tratar de la Corona de Aragón.

La buena historia se hace a base de materiales coetáneos, pero la interpretación puede ser de cualquier época. Una clasificación simplificada de los materiales históricos comprendería dos grupos principales: textos y documentos (más un tercer grupo formado por fuentes epigráficas) ${ }^{12}$.

Sigo bastante de cerca lo que dije en mis ponencias sobre Rasgos de la minoría judía en la Corona de Aragón. (Ribadavia 14-17.10.1991), § 0.2 y Judíos hispánicos: coexistencia, tolerancia, marginación (1391-1492: de los alborotos a la expulsión). (Sevilla 25.11-30.11.1991), $\S 0.3$, que he citado en mi nota 1 . También traté de esta cuestión, pero referida al caso castellano, en Fuentes no castellanas para la historia de los judios de Castilla (Ejemplos de los siglos XIII y XIV), congreso «Proyección histórica de España en sus Tres Culturas». (Junta de Castilla y León, Valladolid, 1993) V.III, 169-176.

${ }_{12}$ Si bien las lápidas suelen ser originales y rara vez están manipuladas, tienen un grave inconveniente: a menudo carecen de puntualización cronológica y geográfica. Añádase a ello que demasiados investigadores olvidan que se trata de bienes muebles. 
Al hablar de textos mi atención se dirige sobre todo a los textos históricos por excelencia, es decir, las crónicas; pero no descuido otros textos no cronísticos, de diversa índole. Cuando pienso en documentos me refiero tanto a originales como a copias o resúmenes coetáneos, frecuentemente reunidos en registros y a la de veces en otras compilaciones.

A mi modo de ver, desde el punto de vista histórico lo esencial son sobre todo las noticias documentales y no las que derivan de textos. Opino que en general hay un valor histórico decreciente: las fuentes más útiles y seguras son, en este orden, las documentales, las textuales y muy por debajo las epigráficas. Hay !ın problema básico: aunque es indudable que algunos documentos son falsos, en general no lo suelen ser; debe subrayarse que los documentos contienen las dos coordenadas históricas fundamentales: la fecha y el lugar. En cambio, los textos absolutamente todos llegan manipulados, en mayor o menor medida, pues heurísticamente nunca son fuentes de primera mano ${ }^{13}$.

Insisto en que el problema del valor que debe concederse a los textos y a los documentos es más general y de mayor alcance. $Y$ no sólo en el caso de los judios. En otra ocasión he enunciado la siguiente ecuación:

[1] cantidad de documentación $\mathrm{x}$ imaginación = constante.

¿Puede aceptarse esto $\sin$ menoscabo de la dignidad del historiador?

\subsection{Las fuentes escritas}

Hace ya años presenté en Toronto una ponencia ${ }^{14}$ comprehensiva sobre los judíos de la Corona de Aragón, en la que expuse unas ideas que aún hoy suscribo, sin perjuicio de matizar mis afirmaciones. Me referí entonces con algún detalle a la situación heurística de la Corona de Aragón ${ }^{15}$, tema en el que ahora voy a insistir un poco.

\footnotetext{
13 Una primera exposición de estos conceptos podrá leerse en el \$2.0 mi artículo Llull e la cultura ebraica, Llull e la cultura ebraica. Tentativo di sistematica, - «Annali. Sezione Romanza» XXXIV (= «Atti del Convengo Internazionale Ramon Llull, il lullismo internazionale, i'Italia» [Napoli 30 e 31 marzo, 1 aprile 1989], Napoli 1992), 171-189. Y una segunda redacción en Fuentes no castellanas para la historia de los judios de Castilla (Ejemplos de los siglos XIII y XIV) (citada en mi nota 11).

14 Fue presentada en el congreso «Jews and Conversos in Late Medieval and Renaissance Spain" (30.4-1.5.1979). Se publicó al cabo de cierto tiempo Romano, David, "Les juifs de la Couronne d'Aragon avant 1391", Revue des Études Juives (Paris), CXLI (1982), 169-182, reimpresa en Romano, David, De historia judia hispánica (Barcelona, Universitat de Barcelona, 1991), 283-296.

$15 \S 1$ : «La documentation accesible» de la ponencia citada en mi nota anterior.
} 
De buenas a primeras, hay que señalar una característica esencial: en la Corona de Aragón se conservan muchísimos documentos cristianos, mientras que su número es relativamente reducido para la Corona de Castilla y para los reinos de Navarra y Portugal (y no digamos para las demás naciones europeas). De las varias clasificaciones posibles, una de ellas consiste en distinguir las fuentes cristianas de las fuentes judías.

\subsubsection{Fuentes cristianas $^{16}$}

Las fuentes no hebreas, en latín y en romance, normalmente son de origen cristiano. $Y$ digo «normalmente» porque a las veces también las hay de origen judío (como lo son, por ejemplo, las ordenaciones de las aljamas). Estas fuentes pueden clasificarse en dos grupos: documentación oficial y documentación no oficial.

Estos documentos nos presentan a los judíos vistos por cristianos porque se trata de documentos cristianos. Según algunos eruditos eso plantea el interrogante de saber hasta qué punto es válida esta información desde el punto de vista judio ${ }^{17}$. Claro que lo contrario, o sea, conocer el punto de vista judío respecto de los cristianos es imposible o casi: habría que analizar los Responsa, cuantitativamente escasos, y siempre entretejidos de jurisprudencia, amén de subjetividad.

Para la historia judía el acervo documental de las naciones hispánicas es extraordinariamente rico en comparación con el de los demás países europeos. Y entre los hispánicos, el lugar preferente le corresponde con mucho a la Corona de Aragón.

Textos los hay en todas las naciones hispánicas; documentos originales, también. En cambio, recopilaciones documentales coetáneas de cierta amplitud sólo se conservan en la Corona de Aragón: me refiero sobre todo a las copias reunidas en registros (Cancillería real, Real Patrimonio, municipios, etc.) así como a los borradores o copias notariales. Esta supervivencia documental favorece generosamente las perspectivas de la historia de la Corona de Aragón, en nuestro caso de la historia judía de la Corona de Aragón. Además, cabe utilizarlas como modelo para las

Para la Corona de Castilla, véanse en especial los $\$ \S 0.1-0.3$ de mi Fuentes no castellanas para la historia de los judios de Castilla (ejemplos de los siglos XIII y XIV) (citado en mi nota 11).

15 Una primera redación de estas ideas figura en Romano, David: Judíos hispánicos: coexistencia, tolerancia, marginación (1391-1492: de los alborotos a la expulsión), ponencia presentada en Sevilla, que he citado en mi nota 1), $\$ 0.3$.

${ }_{17}$ Véase mi nota 3. 
demás naciones hispánicas ${ }^{18}$, con algunas precauciones y reservas, teniendo presentes las diferencias. Ya sé que es preciso aplicar el dicho francés de que «la plus belle fille du monde ne peut donner que ce qu'elle a»; pero de ahí a que todas las visiones históricas amplias de lo que se califica como «España» se basen en la Corona de Aragón media un abismo: el ejemplo paradigmático es el de la obra de Neuman ${ }^{19}$, que mezcla naciones, estados y épocas diversas.

Volviendo a las fuentes de la Corona de Aragón, una primera subclasificación podría ser la antes indicada: oficiales y no oficiales (o privadas).

Las fuentes oficiales responden a varios tipos de organismo. En primer lugar hay que considerar las nacionales de la Corona de Aragón (Archivo de la Corona de Aragón) ${ }^{20}$; luego, las estatales (Archivo del Reino de Valencia, Archivo del Reino de Mallorca) ${ }^{24}$, así como las dimanantes de la propiedad privada del soberano (Archivo del Real Patrimonio). Por último, las municipales. Esas fuentes se conservan muy aisladamente para el siglo XIII, son relativamente abundantes para el XIV y muchísimo más aún para el $x v^{22}$.

En cuanto a las privadas, las más destacadas e interesantes son las notariales, de protocolos ${ }^{23}$, entre las que deben recordarse los llamados Libri judeorum catalanes ${ }^{24}$. Ocasionalmente, pero no por sí mismos, pueden ser útiles los archivos eclesiásticos.

\subsubsection{Fuentes judías}

Fuentes judías las hay en latín/romance y en hebreo. Las primeras no nos han llegado aisladas, sino incorporadas a las cristianas, de las que he tratado antes.

18 Véase mi nota 70 , donde me refiero al trabajo modélico de Asunción Blasco.

19 NeUman, The Jews in Spain. Their social, political and cultural life during the Middle Ages (citado en mi nota 7 ).

20 Véase lo que diré luego, en el § 4.2.

21 Del reino de Aragón no parece que se haya conservado un archivo propio.

22 En la Corona de Castilla únicamente quedan unas cuantas del siglo Xv. Y algo semejante pasa en Navarra.

${ }^{23}$ Sobre la desaparición de las de Lérida, véase $\$ 4.4$.

24 No los había ni en Barcelona ni en Gerona, por razones que ahora sería largo explicar. El texto completo de un Liber iudeorum fue publicado por Montserrat Casas en el volumen Ollich CASTANyer, Immaculada; y CaSAS NADAL, Montserrat, Els "Libri iudeorum" de Vic i Cardona.- C.S.I.C. Institució Milà i Fontanals (Miscel.lánia de textos medievals 3). -Barcelona 1985,350 págs. $(24 \times 17)$. 
Las fuentes en hebreo pueden clasificarse en tres grupos: crónicas, documentos y responsa. Estas fuentes nunca, en ningún caso, son de origen cristiano.

El número de crónicas es bastante reducido, todas están editadas y casi todas traducidas al español. No hay específicas de la Corona de Aragón.

En cuanto a los documentos en hebreo, será preciso compilar una colección única de todos los existentes, tanto los publicados como los inéditos, que aún hay. En este caso concreto debe decirse que la Corona de Aragón no está más favorecida que las demás naciones hispánicas, pero existen documentos hebreos por desentrañar, por ejemplo, los que se usaron para formar el grueso de las encuadernaciones ${ }^{25}$. La recopilación que propongo no debiera limitarse geográficamente, sino extenderla a todas las naciones hispánicas; además, convendría acompañarla de un estudio jurídico.

Los responsa ${ }^{26}$ no son inéditos, pero falta utilizarlos desde un punto de vista histórico. Los hay emitidos tanto por rabinos de la Corona de Castilla como de la Corona de Aragón; pero los interlocutores son de muchas naciones, aunque más de la Corona de Aragón, hecho que no siempre es manifiesto. Las colecciones más importantes de la Corona de Aragón son -las cito por el acrónimo hebreo- las de Rašbá (para fines del siglo xIII y quizás principios del XIV) ${ }^{27}$ y de Ribaš (fines del siglo XIV) ${ }^{28}$. Por dar un ejemplo, Ribaš incorpora un fragmento del estatuto de la aljama de judíos de Barcelona del año 1327, texto que transcribe en catalán, pero con caracteres hebreos: eso permite confirmar la exactitud de la versión conservada en el Archivo de la Corona de Aragón ${ }^{29}$.

\footnotetext{
25 Véase Romano, David, "Documentos hebreos del siglo XIV, de Cataluña y Mallorca", Sefarad (Madrid-Barcelona), XXXIV (1974), 289-312, reimpreso en RoMANO, David, De historia judia hispánica. Universitat de Barcelona, Barcelona 1991, 183-206. En este artículo se citan otros del mismo tema.

${ }_{26}$ Para una sucinta relación de los hispánicos, véase LAREDO, A[BRAHAM] I., "Las «Sěelot u-těšubot» como fuente para la historia de los judíos españoles", Sefarad (Madrid- Barcelona), V, 1945, 441-456. Un índice temático figura en ELON, Menachem, Digest of the Responsa Literature of Spain and North Africa (en hebreo). The Hebrew University (Institute for Research in Jewish Law y Magnes Press). Jerusalem 1987, 314 págs. $(28 \times 22)$.

${ }_{27}$ EPSTEIN, Isidore, The responsa of $R$. Solomon ben Adreth of Barcelona (1235-1310) as a source [of the history of the Jews] of Spain. London $1925, \mathrm{XI}+122$ págs. $(23 \times 15,5)$. Existe una reimpresión de Ktav, New York 1968.

28 Hershman, Abraham M., Rabbi /saac ben Sheshet Perfet and his times. The Jewish Theological Seminary of America. New York 5704/1943. XII + 263 págs. $(21,5 \times 13)$.

${ }_{29}$ Fue publicada por BAER: Die Juden im christlichen Spanien. Urkunden und Regesten (obra mencionada en mi nota 61 ), vol. $1, n{ }^{\circ} 189$
} 
El estudio de esos responsa unido a otros textos permitiría resolver una cuestión que preocupa, o "personalmente me preocupa»: saber qué pensaban los judíos de los cristianos.

\subsection{Fuentes arqueológicas}

Se habla mucho, y con bastante ligereza, de restos arqueológicos hispanojudíos. El caso más notable es el de Gerona ${ }^{30}$ : no hay duda de la zona donde se hallaba el "call», pero delimitarlo e identificar edificios me parece tarea muy atrevida. De 10 que hoy queda, nada es seguro que fuera judío. Los documentos hablan (en Gerona y en otras muchas ciudades) de sinagoga, carnicería, baños, hornos, pescadería, etc.; pero tengo muchas dudas de que fueran realmente edificios (exentos o no): pienso que podían ser fragmentos o partes o rellanos o alas de un edificio.

He hecho varias referencias a casos catalanes, pero mi pregunta concreta es: ¿cómo se sabe que un resto arqueológico es realmente judío? Caben dos posibilidades: a) que lo digan inequivocamente documentos, y b) que se hayan encontrado in situ elementos coetáneos, quiero decir, lápidas. Desde mi punto de vista, estas condiciones no se dan en ninguno de los restos arqueológicos catalogados como judíos ${ }^{3 \dagger}$.

Las lápidas son bienes muebles y no inmuebles, y constan fehacientemente ejemplos de uso para otros fines (abrevaderos, piedras de construcción, para escribir detrás inscripciones posteriores, etc.). Y lo mismo cabría decir de los anillos y pendientes ${ }^{32}$, excepto (como es el caso de las piezas barcelonesas) cuando consta que se hallaron durante la excavación del cementerio. El hallazgo in situ parece decisivo para la identificación como judío, hecho que debe darse precisamente en los cementerios ${ }^{33}$. Únicamente el caso de Barcelona es indiscutible: porque se hizo la excavación, se conocen los tipos de sepulturas antropomorfas, y los restos humanos, aún conservados, han sido estudiados científicamente.

30 Traduzco, adaptando, lo dicho en Romano, David, «La història dels jueus a Catalunya: problemàtica i perspectives, Revista de Catalunya (Barcelona), nova etapa, 3, 1986, § 3.3, “L'arqueologia jueva a Catalunya».

31 Sí se dan casos concretos de las sinagogas de El Tránsito de Toledo y de Córdoba. En cuanto a Santa María la Blanca de Toledo, no tengo la seguridad de que realmente fuera un edificio judío.

32 Véanse las referencias a los trabajos de Durán-Millás y de Altisent, en mi artículo que citaré en la nota 37 .

33 Hay que recordar el hallazgo del siglo pasado en Lérida: era un cementerio erróneamente clasificado como ibérico. 
Pese a esas dificultades y/o limitaciones, creo que hay que incrementar el acervo de piezas arqueológicas judías. Hay que partir del examen pormenorizado de los materiales existentes ${ }^{34}$. Pero es imprescindible planear sistemáticamente una actividad futura. Para ello tiempo atrás propuse un proyecto concreto sobre Gerona ${ }^{35}$ y propongo ahora, con mayor amplitud, realizar un plan de excavaciones, concretamente en dos sectores.

El primer sector sería el de los cementerios. Hay que eliminar o superar las trabas (del tipo que sean) que se oponen a completar lo iniciado en Barcelona ${ }^{36}$; iniciar, en serio, la labor en Gerona y en Zaragoza, examinar bien las posibilidades de Teruel, etc. Al parecer, hay que renunciar a Lérida y a Valencia ${ }^{37}$.

El segundo sector es más problemático a causa de que la zona en cuestión está ocupada por el núcleo urbano actual, formado después de haber destruido los restos preexistentes. Estoy pensando en las juderías mismas, trabajo necesario para aclarar muchas cosas, como la de los hábitats, de lo que hablaré más adelante ( $\$ 4.7$ ).

Para uno y otro sector existe una dificultad importante: la falta de técnicos especializados en arqueología medieval judía. Pero me atrevo a hacer una propuesta: encargarlo a la Dra. Immaculada Ollich, de la Universidad de Barcelona, que ha realizado y realiza excavaciones de arqueología medieval y que, además - esto es muy importante-, ha trabajacio documentalmente sobre judíos ${ }^{38}$.

34 Romano, David, "Arqueología judía en Cataluña», en Actas del III Congreso Internacional Encuentro de las tres culturas. (Toledo 1988), 131-136 reimpreso en Romano, David, De historia judía hispánica. (Barcelona, Universitat de Barcelona, 1991), 415-420.

Desde otro punto de vista me referí a las Possibilitats per a l'arqueologia jueva a Catalunya, en una conferencia pronunciada en las "IV Jornades d'Arqueologia medieval a Catalunya" (Barcelona 21.4.1989).

Supongo que habría que hacer lo mismo para los demás estados de la Corona. Por otra parte, ignoro cuál es la situación en la Corona de Castilla, en Navarra y en Portugal.

35 Romano, David, "Primer balanç valoratiu de les Jornades", en Jornades d'Història dels jueus a Catalunya. Girona abril 1987 (Girona, Ajuntament, 1990), 341-342.

36 Durán Sanpere, A[gustín]; y Millás Vallicrosa, J[osé] M[aría]: “Una necrópolis judaica en el Montjuich de Barcelona, Sefarad (Madrid-Barcelona), VII (1947), 231-259.

37 Romano, David: «Restos judíos en Lérida», Sefarad (Madrid-Barcelona), XX, 1960, 50-65, y “Cementerios judíos de Lérida», Sefarad (Madrid-Barcelona), XXX, (1970), pág. 365. Los dos trabajos se han reimpreso en Romano, David, De historia judia hispánica (Barcelona, Universitat de Barcelona, 1991), 101-118 y 143.

Para hallazgos en Valencia, véase DANVILA COLLADO, Francisco, "Arqueología valenciana. Sepulcros de la calle del Puerto", El Archivo. (Valencia), V, 1891, 261-265, y FERnÁndez CASA. Nova, Adolfo, "Informe sobre la necrópolis judaica de Valencia", Boletín de la Real Academia de Bellas Artes de San Fernando (Madrid), XV, 1895, 11-14.

38 Por ejemplo, es autora de un trabajo mencionado en mi nota 24. 


\section{ESTADO DE LA CUESTIÓN}

\subsection{Filosofía, teoría, realidad}

Tiempo atrás, al abordar la problemática hispanojudía en tiempos de Alfonso $X$ de Castilla ${ }^{39}$, expuse de manera deslavazada unas cuantas ideas acerca de la reconstrucción histórica. Esas ideas no han sido desarrolladas de manera sistemática, pero creo que pueden resumirse en tres apartados de denominación inequívoca: filosofía, teoría, realidad.

El caso de la Corona de Castilla, con legislación civil unitaria -no entro ahora en el tema de saber cuál era su inspiración-, es muy distinto del de la Corona de Aragón. En este último no sé, no lo he intentado, si será posible descubrir una filosofía subyacente a la teoría; en caso positivo, habría que ver qué orientación tiene esa filosofía.

Si pasamos a la teoría, quiero decir, la teoría jurídica, sin duda es un tema posible, a pesar de que sólo muy recientemente ha empezado a interesar, tal como luego indicaré.

Más largo y complejo es el análisis de la realidad, sobre el que haré propuestas concretas más adelante ( $\S 4.2-4.11$ ).

Con la documentación publicada y con la bibliografía de que se dispone cabe estudiar muchas cosas; pero yo me atrevería a decir que en general los temas se han planteado pero que rara vez se ha llegado a una solución asequible y válida: son muchos los árboles que faltan para completar el bosque, precisamente en la Corona de Aragón, donde en cierto modo puede hablarse de exceso de documentos.

La verdad es que temas hechos no los hay; «temitas», sí. En cambio, hay temas planteados, iniciados, a medio hacer. Dado el volumen de documentación conservada, aunque es mucho lo que se ha hecho es muchísimo lo que queda por hacer. En consonancia con lo dicho antes ( $\S$ 2.1.1), en términos generales puede decirse que el siglo xIII es relativamente bien conocido, sobre todo porque es poca la documentación que ha subsistido. La cuestión se complica para el siglo xIV: existe bastante información, pero es mínimo lo que se sabe, quizás porque más de la mitad corresponde a un solo reinado, el de Pedro el Ceremonioso. En

39 Romano, David, «Alfonso $X$ y los judíos. Problemática y propuestas de trabajo», Anuario de Estudios Medievales, n. ${ }^{\circ} 15$ (= Estudios dedicados a la memoria de D. Claudio SánchezAlbornoz, Barcelona 1985), 151-177, reimpreso en Romano, David, De historia judia hispánica. (Barcelona, Universitat de Barcelona, 1991), 373-399. 
cuanto al siglo xv, debe prestársele especial atención, pues es la ceniciente de la historia judía de la Corona de Aragón y, aún más, de toda la Península. Recientemente aduje ${ }^{40}$ una prueba bastante objetiva: la versión española del libro de Baer, de un total de 663 páginas (sin contar las notas) dedica a este período (explicado en el capítulo XI) solamente 42 páginas, es decir, poco más del 6 por 100 .

\subsection{El conocimiento de la bibliografía}

Vayamos por partes. El asunto de la bibliografía requiere una atención primaria. Dejando de lado cuanto se refiere a la historia hispánica general, me concentraré en lo específico de la historia judía.

Dada la riqueza documental de los archivos españoles, en especial los de la Corona de Aragón, es lógico que se haya generado un considerable número de publicaciones concretas sobre la historia judía (amén de las que tratan incidentalmente de ella). Ahora bien. La recogida de esas publicaciones deja bastante que desear.

La meritoria relación bibliográfica de Singerman ${ }^{41}$, poco conocida por los historiadores generales, no satisface los deseos del investigador porque presenta dos inconvenientes: uno es la clasificación, históricamente poco útil; otro porque hoy, a las puertas del tercer milenio, es incomprensible no comentar mínimamente las piezas bibliográficas.

Para el reino de Aragón resulta francamente útil y digno de ser imitado el largo estado de la cuestión que escribió Asunción Blasco, que además es crítico ${ }^{42}$. Para Cataluña, Riera ${ }^{43}$ está publicando bibliografía por entregas. El sistema de enfoque (catalán, no catalán) es discutible, pero puede ser remediado con facilidad si se integran los elementos recogidos. La situación no es tan halagüeña para los demás estados ${ }^{44}$.

40 Romano, David, Judios hispánicos: coexistencia, tolerancia, marginación (1391-1492: de los alborotos a la expulsión), § 2.0 , ponencia citada en mi nota 1.

49 Singerman, Robert, The Jews in Spain and Portugal: A Bibliography. - Garland. - New York-London 1975, - 364 págs. (22 x 14).

42 Blasco Martínez, Asunción, Los judios del reino de Aragón. Balance de los estudios realizados y perspectivas, en «l Col.loqui de Història dels jueus a la Corona d'Aragón (Lérida 29-30.11.1989), (Institut d'Estudis llerdencs, Lleida 1991), 13-97.

43 RIERA I SANS, Jaume, «Estudis sobre el judaisme català, Calls (Tārrega) 1 (1986), 93-132; 2 (1987), 181-209; 3 (1988-1989), 103-135; y «Estudis forasters sobre el judaisme català», Calls (Tārrega), 4 (1990), 95-161.

44 Hinojosa Montalvo, José, «En torno a los judíos valencianos: la recuperación de una minoria olvidada", Hispania. (Madrid) L (1990), 921-940. 
Hace mucho tiempo planeé un proyecto, cuya primera formulación mental data de los años cincuenta, de redactar una bibliografía de historia hispanojudía, para la que tengo recogidas muchas piezas debidamente comentadas; pero abrigo fundadas sospechas de que no tendré tiempo suficiente para concluirlo.

\subsection{La visión de las crónicas}

La posibilidad de una aportación de las crónicas es algo que al parecer debe descartarse. Inicié el intento con las crónicas catalanas ${ }^{45}$, con resultados francamente pobres, tal vez por no existir crónicas posteriores a los sucesos de 1391 y de 1492, es decir, los sucesos más destacados, negativamente, del tema que estoy historiando. $Y$ me pregunto: ¿por qué motivo no hay crónicas posteriores?

Por otra parte, no conozco crónicas ni aragonesas ni mallorquinas ni valencianas, historiográficamente válidas se entiende.

Por lo que se refiere a las crónicas en hebreo, su número es bastante reducido, todas están editadas y casi todas traducidas al español.

En pocas palabras: para la Corona de Aragón parece muy reducida la esperanza de una aportación sustanciosa de las crónicas.

\section{CAMINOS DE LA INVESTIGACIÓN}

\subsection{Generalidades}

Después de la problemática que he venido planteando, yo diría que ha llegado el momento de acercarse a los hechos concretos, de sugerir temas de trabajo que abran perspectivas de futuro, cuestión que me obsesiona últimamente, según puede apreciarse incluso por los subtítulos que pongo a mis artículos ${ }^{46}$.

45 Romano, David, Les juifs de la Couronne d'Aragon dans les chroniques médiévales catalanes. En "Xlle Congrès d'Histoire de la Couronne d'Aragon" (= Mémoires de la Société Archéologique de Montpellier, tome XVI, Montpellier 1988), 25-32.

${ }^{46}$ Romano, David, «Marco jurídico de la minoría judía en la Corona de Castilla de 1214 a 1350. (Síntesis y propuestas de trabajo), en Actas del I/ Congreso Internacional: Encuentro de las tres Culturas. (Toledo, Ayuntamiento, 1985), 261-291, reimpreso en Romano, David, De historia judía hispánica. (Barcelona, Universitat de Barcelona, 1991), 341-371. Romano, David, «Alfonso $\mathrm{X}$ y los judíos. Problemática y propuestas de trabajo», Anuario de Estudios Medievales, 15. (= Estudios dedicados a la memoria de D. Claudio Sánchez-Albornoz, Barcelona 1985), 
Pienso, sobre todo, en lo que cabe hacer a base de documentos cristianos, lo que no empece tener presentes las fuentes judías.

Vaya por delante mi afirmación de que no voy a hacer un tratamiento sistemático sino que me circunscribiré a exponer y comentar unos cuantos aspectos característicos, que responden a dos orientaciones: por una parte, los temas en los que parece que nos hallamos cerca de la realidad histórica; por otra, aquellos que conviene tener presentes si de verdad queremos avanzar con cierta perspectiva de futuro.

Los temas que enumeraré se refieren a problemas generales y sólo al final ( $\$ 4.11$ ) sugeriré un par de cuestiones menores, de detalle. Por otra parte, es obligado repetir que ninguno está resuelto o acabado; que algunos ya han sido planteados, unos pocos ya se han iniciado; pero la mayoría de ellos son casi vírgenes.

Podría limitarme a confeccionar una mancolista tal como se hacía a principios de siglo. Sin embargo, creo que no hay más remedio que puntualizar, y que destacar que no todos los temas son de las mismas dimensiones o dificultad: los hay breves o largos en cuanto a la búsqueda; los hay breves o largos en cuanto a la exposición.

He aquí algunos ejemplos. Las teorías y las actividades de fray Vicente Ferrer (1350-1414) exigen un estudio sistemático aunque sólo fuera para decidir si iban dirigidas o no contra los judios ${ }^{47}$; también merece atención particular la actuación de la Inquisición moderna en la Corona de Aragón; lo mismo cabe decir de la proyectada expulsión de los judíos de los obispados de Zaragoza y Albarracín, aunque los resultados puedan ser decepcionantes; $y$, por último, es necesario conocer bien la expulsión de 1492, y de 1493 en el Rosellón.

151-177, reimpreso en Romano, David, De historia judia hispánica (Barcelona, Universitat de Barcelona, 1991), 373-399. ROMANO, David, «La història dels jueus a Catalunya: problemàtica : perspectives", Revista de Catalunya. (Barcelona), nova etapa, 3 (1986), 60-72. Romano, David, Creencias y prácticas religiosas de los judíos de Valencia (1461-1492). Propuestas metodológicas a base de documentos inquisitoriales. Creencias y prácticas religiosas de los judíos de Valencia (1461-1492). Propuestas metodológicas a base de documentos inquisitoriales.-.- En "Luis de Santàngel i el seu temps" (Ajuntament de València, València 1992), 431-448 en "Lluís de Santàngel i el seu temps», (Ajuntament de Valencia, Valencia 1992), 431-448.

A ellos puede añadirse los relacionados con la ocasión en que se gestaron, por ejemplo, Romano, David, "Los judíos de la Corona de Aragón en la Edad Media», en España. Al-Andalus. Sefarad: Síntesis y nuevas perspectivas. (Salamanca, Universidad de Salamanca, 1988), págs. 153-168 -obsérvese el subtítulo «Síntesis y nuevas perspectivas»-.

47 En el congreso de Sevilla (citado en mi nota 1) presentó una comunicación García MarTínez, Antonio Claret, El acoso a las comunidades judias en los milagros bajomedievales. El caso de San Vicente Ferrer. 
Hay temas que son cronológicamente más vastos. Éste es el caso del siglo xV o más concretamente del período entre 1416 y 1479 , que está muy vacío ${ }^{48}$; los reinados largos (Jaime I, Pedro el Ceremonioso, Alfonso el Magnánimo) son de difícil tratamiento, a menos que se logre trabajar en equipo. Otros son duros de resolver por la diversidad de sus partes, por ejemplo, ahondar o rectificar mi exposición sobre las características comparadas de judíos y cristianos $^{49}$, y lo mismo cabe decir de las relaciones de los judíos con el campo ${ }^{50}$.

A todo esto es preciso añadir una observación esencial. He dicho antes (§ 2.1.1) que un tema complejo, pero a la vez muy atractivo y fundamental, sería afrontar la cuestión de conocer el punto de vista judío respecto de los cristianos. ¿Es posible estudiarlo? Sí, aunque sea difícil: habría que analizar los Responsa, cuantitativamente escasos, y siempre entretejidos de jurisprudencia, amén de subjetividad; y también habría que leer muchas fuentes hebreas teóricas.

\subsection{Aspectos teóricos: la legislación ${ }^{51}$}

El estudio del marco jurídico de la situación de los judíos en la Corona de Aragón no puede hacerse con la misma facilidad que para la Corona de Castilla ${ }^{52}$, por un motivo básico y elemental: que no se trataba de una unidad propiamente dicha (por ejemplo, no existían unas cortes únicas sino que cada estado las tenía por separado, aunque se reunieran en la misma ciudad). Entre las varias consecuencias que ello produce destaco dos: 1) la primera es que respecto a los judíos la única legislación cristiana "Común a todos los estados" era, paradójicamente, la eclesiástica papal, pues ni siquiera la eclesiástica nacional/provincial/diocesana era la mis$\mathrm{ma}^{53}$; 2) la segunda consecuencia es que habría que atender por sepa-

48 Léanse las frases insertas al final del \$ 3.0 .

49 ROMANO, David, «Característiques dels jueus en relació amb els cristians en els estats hispànics", en Jornades d'Història dels jueus a Catalunya, Girona abril †987 (Girona, Ajuntament, 1990), 9-27 y 29-43, reimpreso en Romano, David, De historia judía hispánica (Barcelona, Universitat de Barcelona, 1991), 475-493.

50 Abordaré este tema en el $\$ 5.3$.

51 En algunos aspectos sigo de cerca mi ponencia Rasgos de la minoría judia en la Corona de Aragón presentada al congreso sobre «Judíos y conversos en la historia» (Ribadavia 1417.10.1991), que cité en mi nota 1.

52 Véase Romano, David, Marco juridico de la minoria judía en la Corona de Castilla de 1214 a 1350. (Sín tesis y propuestas de trabajo), citado en mi nota 46 .

53 En el caso de la Corona de Castilla para el periodo anterior al año 1350, puede verse el $\S 2.3$ del artículo citado en la nota anterior. 
rado a lo que se legisló en cada estado, lo que normalmente no se ha hecho ${ }^{54}$ y no es fácil hacer.

Por una parte, debiera estudiarse la cuestión de los fueros y cartas pueblas ${ }^{55}$, aunque no tengo demasiadas esperanzas de que esa investigación resulte aclaradora. En cambio, me parece que será francamente interesante conocer a fondo todo cuanto se aprobó en las cortes. Es un trabajo concreto pero sin duda nada fácil, a pesar de que pueda recurrirse a la falsilla de los artículos sobre la situación en la Corona de Castilla ${ }^{56}$. Habría que empezar por recoger las actas relativas a Aragón y a Valencia, ni reunidas ni mucho menos estudiadas; el reino de Mallorca sólo contaba con un "Consell general» y cuando los delegados acudían a cortes no eran cortes propias e independientes sino las de Cataluña. En otras palabras: sólo cabe acercarse a la problemática catalana. Es un trabajo recientemente iniciado por Emma Vila, que acaba de presentar ${ }^{57}$ un ensayo acerca de la legislación sobre judíos en las Cortes catalanas hasta el año 1327.

Debe hacerse una observación muy importante: el estudio de la legislación habría de completarse en todos los casos con una comprobación documental de lo que ocurría en la realidad.

Un aspecto significativo podría proporcionarlo la recogida de los textos legales en hebreo, como las taqqanot de 1354-1355.

\subsection{Publicación de documentos}

Entrando ya en el terreno de la realidad, hablemos ahora de los documentos, tanto en hebreo como en latín o romance.

De vez en vez han ido apareciendo documentos hispanojudíos en hebreo, que se han ido publicando en lugares muy dispares. Hay que pro-

54 Lo he intentado en un caso concreto, al analizar las leyes restrictivas de 1283-1284. Véase Romano, David, Judios al servicio de Pedro el Grande de Aragón (1276-1285). (Consejo Superior de Investigaciones Científicas [Institución «Milá y Fontanals»] y Universidad de Barcelona [Facultad de Filología], Barcelona 1983), págs. 175-178.

55 Habría que partir de las compilaciones de José M. ${ }^{2}$ Font Rius (para Cataluña) y de Miguel Gual Camarena (para Valencia).

56 Pienso sobre todo en los trabajos de LEón TELLO, Pilar, "Legislación sobre judíos en las Cortes de los antiguos reinos de León y Castilla», en IV World Congress of Jewish Studies, vol. II (Jerusalem, World Union of Jewish Studies, 1968), 55-63 y Monsalvo Antón, José María, "Cortes de Castilla y León y minorías", en Las Cortes de Castilla y León en la Edad Media. (Valladolid, Cortes de Castilla y León, 1988), 145-191.

${ }_{57}$ VILA ESTEBAN, Emma, Legislació sobre jueus en les Corts Catalanes fins 1327 (trabajo presentado el 30.9.1991, en la Universidad Autónoma de Barcelona). 
mocionar una recopilación o repertorio de tales documentos (a ser posible, no sólo de la Corona de Aragón) y darla a luz, mejor con un estudio jurídico, contrastivo si cabe, de las condiciones en las diversas naciones hispánicas ${ }^{58}$.

La documentación emitida por autoridades o fedatarios cristianos es mucho más abundante y se ha dado a conocer muy esparcidamente -la publicación ha sido bastante escasa: en este aspecto la época positivista no fue muy fructífera en España ${ }^{59}$-. Dejemos de lado la que figura en obras de tema no judío; pero hay trabajos específicamente dedicados a hispanojudíos, en que los documentos se dan a conocer sea en regest um sea por entero. Casi un siglo de antigüedad (1894) tiene el repertorio de Jacobs, de ámbito geográfico amplio, al que siguieron las entregas de Régné (1910), ya concretadas a la Corona de Aragón, que hace años comenté conjuntamente ${ }^{60}$. Años más tarde, exactamente en 1929 Baer editó su primer volumen de materiales ${ }^{61}$, en realidad apéndice documental del libro que publicaría mucho después ${ }^{62}$.

Las tres obras han servido a los investigadores, que han utilizado sobre todo las dos últimas, pero muy poco la de Jacobs. Añádanse publicaciones de reducido ámbito geográfico y/o cronológico ${ }^{63}$. Sin embargo, es indudable que habría que editar otros repertorios más: eso no se hará porque se trata de un trabajo que hoy se califica de... poco inteligente.

58 Esta idea la he explicado con algún detalle más en el $\$ 2.1 .2$ de esta ponencia.

59 Véase lo que dije en $\S 0$. de Romano, David, Creencias y prácticas religiosas de los judíos de Valencia (1461-1492). Propuestas metodológicas a base de documentos inquisitoriales, citada en mi nota 46.

60 Romano, David, "Análisis de los repertorios documentales de Jacobs y Régné", Sefarad. (Madrid-Barcelona), XIV, (1954), 247-264, reimpreso en RomANo, David, De historia judia hispánica. (Barcelona, Universitat de Barcelona, 1991), 25-42.

JACOBS, Joseph, An inquiry into the sources of the History of the Jews in Spain.- London 1894,- XLVIII + 263 págs. $(22,5 \times 14,5)$.

RÉGNE, Je גn, History of the Jews in Aragón. Regesta and Documents 1213-1327. (Jerusalem, The Hebrew University, 1978), reimpresión del "Catalogue des actes de Jaime I ${ }^{\mathrm{er}}$, Pedro III et Alfonso III rois d'Aragon, concernant les juifs (1213-1291)" y del "Catalocue d'actes pour servir à l'histoire des juifs de la Couronne d'Aragon sous le règne de Jaime II (1291-1327)", publicados en la Revue des Études Juives. (Paris), LX, 1910, (23, 5 x 15,5).

61 BAER, Fritz, Die Juden im christlichen Spanien. Urkunden und Regesten, 2 vols. Berlin 1929-1936 (reimpresión Greg, England 1970). El segundo, sobre Castilla y la Inquisición, se publicó en 1936.

62 BAER, Yitzhak, Historia de los judios en la España cristiana. Trad. José Luis Lacave. Madrid, Altalena, 1981, 1 tomo en 2 vols.: XXIV + 836 págs. $(21,5 \times 13,5)$. La primera edición en hebreo es del año 5705/1944-45.

63 Un primer conocimiento de ellos puede lograrse mediante el repertorio de Singerman (citado en mi nota 41); pero es indudable que la información debe actualizarse. 
Pero opino que es un desideratum acuciante, incluso si quien da a conocer esos materiales no los utiliza por sí mismo.

\subsection{Historias de reinados}

Carecemos de visión global de la vida judía en cualquier reinado de la Corona de Aragón ${ }^{64}$, aunque haya apuntes de cierta amplitud sobre algunos. Es tarea urgente que podría empezarse por los más cortos, más abarcables, por ejemplo, el de Fernando I de Antequera ${ }^{65}$. Sin embargo, es preciso planear el trabajo para los reinados largos, superiores a los cuarenta años y uno incluso de más de sesenta. Para éstos es muy posible que sea adecuado pensar en un trabajo de equipo, dada la mole informativa que es preciso recoger y elaborar.

El más favorecido es el de Jaime I (1213-1276), por dos motivos: 1) por lo que ya se ha hecho y 2) porque el acervo documental no es excesivamente grande, pues la cancillería real no se organizó hasta \pm 1252 y seguramente tampoco lo estaba la municipal y -esto es una suerte y a la vez una desgracia - casi no quedan registros notariales.

El reinado de Pedro el Ceremonioso (1336-1387) me parece francamente interesante, tal vez porque he husmeado un poco en él ${ }^{66}$.

En cuanto al de Alfonso el Magnánimo (1416-1459) se diría que es complejo desde el punto de vista heurístico: la Dra. Blasco ha planteado el problema de saber dónde se hallan las fuentes que debieran utilizarse. En una de mis primeras publicaciones ${ }^{67}$ no me di cuenta de esa dificultad. Después, al hojear algunos estudios de Piles ${ }^{68}$, me ha parecido que parte de la documentación que puede ser útil se conserva en el Archivo del Reino de Valencia ${ }^{69}$.

64 No es mucho mejor la situación en la Corona de Castilla. Un primer planteo puede verse en Romano, David, Alfonso $x$ y los judios. Problemática y propuestas de trabajo (citado en mi nota 46 ).

${ }_{65}$ Sobre este período trabaja Francisca Vendrell, que ha publicado varios artículos, sobre todo en la revista Sefarad.

66 Ya lo señalé en Romano, David, «Els jueus en temps de Pere el Cerimoniós», en Pere el Cerimoniós i la seva època. (Barcelona, Consell Superior d'Investigacions Científiques/Institució Milà i Fontanals, 1989), pág. 115, reimpreso en Romano, David, De historia judia hispánica. (Barcelona, Universitat de Barcelona, 1991), pág. 457.

${ }_{67}$ Romano, David, «Los judíos de la Corona de Aragón en la primera mitad del siglo Xv», en Actas y Comunicaciones del $N$ Congreso de Historia de la Corona de Aragón, I. (Palma de Mallorca, Diputación Provincial de Baleares, 1959 [1961]), 239-249, reimpreso en RomANo, David, De historia judia hispánica. (Barcelona, Universitat de Barcelona, 1991), 119-129.

${ }_{68}$ Véanse algunos de los artículos que publicó en la revista Sefarad.

69 En diversos archivos se basa el artículo de KuCHLER, Winfried, «Besteuerung der Juden 


\section{4 riistorias locales}

Un problema semejante se da con las aljamas. Queda suficiente, mucha, a menudo demasiada, documentación - confróntese con la situación de la Corona de Castilla - para trazar la historia de cualquiera de ellas; y casi nada se ha hecho, ni siquiera con las pequeñas. En cuanto a las grandes, algunas acabaron en fechas relativamente tempranas, por ejemplo, Barcelona y Valencia desaparecieron en 1391 y Palma de Mallorca en 1435. Ninguna de ellas logró ser restablecida, y a menudo me pregunto: ¿por qué?

La consecuencia es que sólo subsitió una aljama realmente importante, la de Zaragoza, que, como ha dicho Asunción Blasco, asumió la dirección política e intelectual del judaísmo de la Corona. El amplio estudio que ella misma ha realizado hasta aproximadamente el año 1415, esperamos que sea completado para el siglo $x V$ - recuerdo que es el más ignorado de la historia hispanojudía-.

Precisamente la tesis doctoral de la Dra. Blasco ${ }^{70}$, basada en los fondos notariales zaragozanos, representa un magnífico e inmejorable guión para cualquier historia de una comunidad o núcleo hispanojudío.

A mucha distancia, por debajo, pueden utilizarse dos síntesis mías, una sobre Barcelona, publicada sin notas ${ }^{71}$, y otra, anotada, referente a Lérida ${ }^{72}$, ciudad para la que existe una notable dificultad: los protocolos notariales desaparecieron hace más de cincuenta años ${ }^{73}$. Para Gerona el investigador dispone de una cómoda herramienta auxiliar: la reimpresión

und Mauren in den Ländern der Krone Aragons während des 15. Jahrhunderts", Gesammelte Aufsätze zur Kulturge-schichte Spaniens. (Münster), n. ${ }^{\circ}$ XXIV, 1968, 227-268.

70 Hasta ahora sólo se ha editado el primer volumen, o sea, BLAsco Martínez, Asunción, La judería de Zaragoza en el siglo xIV. Zaragoza, Institución Fernando el Católico, 1988, 321 págs. $(2 \uparrow \times 13)$. Sin embargo, el investigador puede consultar el detallado índice general publicado, junto con un breve resumen, en la ponencia de BlAsco, Asunción, «Los judíos de Zaragoza. Un modelo para investigación», en Jornades d'Història dels jueus a Catalunya. Girona abril 1987 (Girona, Ajuntament, 1990), 177-215 y 217-221.

71 Romano, David, «La Aljama de Judíos de Barcelona en el Siglo xIv», en De Sefarad. Los Judíos de la Corona de Aragón en los Siglos x|V.xv. (Valencia [1989]), 43-54.

72 Romano, David, Els jueus de Lleida, ponencia presentada en el « 1 Col.loqui de Història dels jueus a la Corona d'Aragó». (Lérida 29-30.11.1989), (Institut d'Estudis Ilerdencs, Lleida 1991).

${ }_{73}$ Existe la posibilidad de valerse de materiales conservados en otros archivos de protocolos. Véase, por ejemplo, SECALL I GüELL, Gabriel, «Aportació històrica als jueus Ileidatans. Segles XIII-XV», /lerda (Lérida), XLVI, 1985, 273-288.

Más afortunadas son las ciudades de Cervera y Tárrega, en la actual provincia de Lérida. 
conjunta de numerosas aportaciones concretas ${ }^{74}$. Con todo eso, la labor resulta bastante simplificada. Es un ejemplo digno de imitación, por ejemplo para Barcelona ${ }^{75}$.

\subsection{Organización de las aljamas}

En estrecha relación con lo indicado en el apartado anterior debe considerarse la información acerca de la historia interna de esas aljamas, o de cualquiera de ellas en particular.

Aparte de la exposición de Neuman ${ }^{76}$, yo mismo he resumido el estado de la cuestión en una síntesis divulgativa ${ }^{77}$ que aborda los siguientes puntos, que cito sumariamente: 1) indicaciones generales; 2) leyes, reglamentos y privilegios; 3) las instituciones: asamblea, consejo, secretarios, otros cargos civiles y religiosos. Sin embargo, estoy convencido de que quien quiera adentrarse en ello lo mejor que puede hacer es seguir el detallado guión publicado por Asunción Blasco ${ }^{78}$.

En otras ocasiones ${ }^{79}$ he señalado que tal vez haya que fijarse en las ordenaciones de las aljamas: el ejemplo más destacado son las ordenaciones de la aljama de Barcelona, de los años 1327 y 1386. La primera, o sea, la de 1327 (un fragmento de la cual está copiado en un responsum de Ribaš) sirvió de modelo a las aljamas de Valencia de 1364 y de Huesca de 1374, ambas escritas en catalán (incluso la de Huesca), que están pidiendo un estudio comparado (ya iniciado). Grupo aparte forman las ordenaciones de la aljama de Zaragoza de 1382 y de Barcelona de 1386, muy parecidas y quizás relacionadas entre sí.

\subsection{Organizaciones supralocales ${ }^{80}$}

Una cuestión, sin duda interesante, la plantean las agrupaciones supralocales, hechas siempre o casi siempre con finalidad fiscal.

\footnotetext{
74 Romano, David, Per a una història de la Girona jueva.- Introducción y selección.-Girona, Ajuntament de Girona, 19882 vols., 788 págs. (24,5-17).

${ }_{75}$ Pienso en un volumen que podría titularse Per a una història de la Barcelona jueva, que reuniera to recogido en Singerman.

${ }_{76}$ Véase lo que dije en el texto pertinenie a la nota 7.

77 Está citada en mi nota 10.

78 Lo he mencionado en mi nota 70.

79 Romano, David, Los judíos de la Corona de Aragón en la Edad Media (citado en mi nota 46), \$ 0.4 y Rasgos de la minoría judía en la Corona de Aragón (citado en mi nota 1).

80 Resumo parte del $\S 4$ de Romano, David, Habitats urbains des juifs hispaniques, Habitats urbains des juifs hispaniques.- En "Les sociétés urbaines en France méridionale et en Péninsule lbérique au Moyen Age» (París 1991), 421-434.
} 
La principal de ellas es la colecta (también llamada cullita y commune), reunión de varias agrupaciones judías junto con una aljama, que da nombre a la zona. El nombre y la definición son claros en la Corona de Aragón, pero falta determinar los límites que tenían cada una de esas colectas: sólo los he podido reconstruir parcialmente en el caso de Gerona. (En la Corona de Castilla no existe denominación explícita, aunque parece incuestionable la existencia de colectas).

Otras agrupaciones que deben estudiarse son: 1) las reuniones de aljamas (o colectas) de un mismo estado, que se producen por una sola causa: para distribuir subsidia, es decir, impuestos extraordinarios ${ }^{81}$; 2) alguna vez está documentada la "centena aljamarum", que no sé qué significa exactamente; y 3) en una sola ocasión, que sepamos, los diversos estados de la Corona intentaron juntarse: así lo da a conocer el texto hebreo que constituye lo que suelen llamarse taqqanot del año 5115, o sea, 1354-1355.

\subsection{Los hábitats}

Una investigación mía ${ }^{82}$ acerca de la relación entre los judíos hispánicos y el campo me ha llevado a establecer que no había hábitats rurales judíos. Por el contrario, tal como expuse en otro lugar ${ }^{83}$, parece evidente que se agrupaban en hábitats urbanos, que básicamente podían ser de tres tipos: 1) el «barrio», habitado por un número elevado de judíos, que normalmente constituian una aljama; 2) la «calle», a lo largo de la cual había establecidos judíos que no llegaban a formar aljama, sino que correspondían a lo que provisionalmente yo denomino «núcleos»; y 3) los judíos "aislados" en un ambiente cristiano (y es preciso distinguir entre los judíos que se hallan accidentalmente EN un lugar y aquellos que son habitantes DE un lugar).

Para confirmar (o rechazar) mis hipótesis acerca de los hábitats urbanos (barrios o calles) habría que realizar las investigaciones arqueológicas antes (final del § 2.2) sugeridas. Por desgracia, eso es bastante difícil, porque muy a menudo la zona urbana medieval ha sido derribada

81 Romano, David, «El reparto del subsidio de 1282 entre las aljamas catalanas», Sefarad. (Madrid-Barcelona), n. $.^{\circ} \mathrm{XII}, 1953,73-86$, reimpreso en Romano, David, De historia judia hispánica. (Barcelona, Universitat de Barcelona, 1991), 11-24.

82 Hablaré de este asunto en el $\$ 5.3$.

¿3 Véase el $\S 4$ de Romano. David, Habitats urbains des juifs hispaniques (citado en mi nota $80)$. 
o destruida (por ejemplo, en Zaragoza), aunque algunas veces ha quedado si no intacta al menos bien delimitada (Barcelona, Gerona). Dadas estas premisas, el único camino practicable es el análisis documental, pese a su complejidad y, sobre todo, por la inseguridad inherente a transformar datos archivísticos en resultados arqueológicos.

\subsection{La demografía}

Extraordinariamente interesante, pero no sabría afirmar hasta qué punto puede desembocar en algo sólido, es el intento de aproximarse a la cuestión demográfica. Es tema al que dediqué una amplia conferencia, que dudo mucho que llegue a publicarse, al menos en la forma en que la expuse en su día ${ }^{84}$. Pero para guía de los interesados en el tema reproduzco en apéndice el guión repartido y copio aquí las conclusiones de ese primer planteo, a mi parecer sistemático, de los medios para determinar las cifras de la población judía de la Corona de Aragón, partiendo del hecho de la inexistencia de censos demográficos. Para ello he examinado el posible valor y utilidad de los censos históricos conocidos: 1) censos fiscales generales; 2) listas de pagos de las aljamas de judíos; 3) listas nominales de unidades familiares, con prorrata o sin ella. Asimismo, he sugerido 4) la posibilidad de crear censos demográficos y 5) la conveniencia de analizar noticias de segunda mano expuestas en fuentes no documentales o por historiadores.

En previsión de que puedan usarse listas de cabezas de familia, he abordado el tema del coeficiente familiar por el que habría de multiplicarse el número de cabezas de familia para fijar el total de habitantes judíos: como hipótesis de trabajo puede utilizarse el coeficiente 4,5.

La impresión general es que la importancia numérica de los judíos era pequeña (aunque su importancia económica proporcionalmente fuera algo mayor). Pero el resultado, por ahora, es que no veo la manera de calcular el número de judíos, aunque a largo, muy largo plazo, quizás las listas nominales puedan ser el medio más seguro, o mejor dicho, el menos dudoso para llegar a resultados, para fijar mínimos.

B4 Romano, David, Para una demografía judía de la Corona de Aragón: Planteo sistemático para determinar cifras de población, pronunciada en Madrid (27.8.1990), en la reunión titulada "Spanish Jewry and its dispersion: Its influence on the history of Spain and on Jewish history" (en una reunión anexa al 17 th International Congress of historical sciences). 
Las pocas conclusiones a las que se puede llegar por ahora se refieren a dos puntos: 1) el valor del término «minoría», y 2) el cálculo en cifras absolutas.

Para determinar el valor del término «minoría», es decir, el porcentaje de judíos en relación con el número de cristianos, no pueden tomarse en consideración sugerencias o afirmaciones de historiadores actuales que no son más que juegos malabares, sino que deben analizarse sistemáticamente los «fogatges-monedatges-morabatins»: en este sentido las más útiles hasta ahora son las cifras referentes a Mallorca, pues los documentos de Cataluña no han sido vistos desde esta perspectiva, y los de Valencia y Aragón tampoco.

Aparentemente válidos serían los «fogatges" que indicaran nombres, a pesar de que el único caso conocido (el de Gandía) resulte desorientador cuando se le somete a comparación.

En cuanto a cifras absolutas de población, el camino tan sólo se ha desbrozado ligeramente: podemos creer que estamos cerca de la realidad únicamente para localidades de poca población judía, pero no para las aljamas de mediano tamaño ni para las grandes, en algunas de las cuales (Zaragoza, Calatayud, etc.) debe tenerse en cuenta que vivían familias judías que gozaban de franquicia fiscal: lógicamente no solían aparecer en las listas de contribuyentes. Además, no siempre se señala la presencia de pobres y miserables exentos de pago (sí se indican en el caso de Gandía, y otros).

Sintetizando, yo me atrevería a decir que los cálculos pueden hacerse de este modo: a) utilizar las listas nominales para los judíos de las ciudades pequeñas; b) crear censos estadísticos para los que habitaban en ciudades medianas y grandes (para las cuales el método de las listas nominales parece que no sirve).

Este intento no pretende ser más que un toque de atención hacia el tema, que espero que pueda servir no sólo de catalizador de datos conocidos por los historiadores sino también como acicate para futuras investigaciones sistemáticas. 


\subsection{Los impuestos}

El tema de los impuestos tampoco ha atraído el interés de los investigadores. Por desgracia, en la Corona de Aragón no quedan padrones fiscales judíos, como los tenemos en la Corona de Castilla ${ }^{85}$.

En principio podría pensarse que esto fuera debido al hecho de que no se trataba de una nación unitaria sino de un conglomerado de estados aunados por la unión en la persona del soberano. Pero la verdad es que tampoco conozco - no digo que no los haya- padrones fiscales por separado de los judíos de cada uno de los estados que integraban la Corona: ni de los reinos de Aragón, Mallorca o Valencia, ni tampoco de Cataluña. Hoy en día la única posibilidad parecen ofrecerla las listas de pagos hechas en ocasiones muy concretas, muy dispersas en los registros de la cancillería, tanto si se trata de los impuestos normales como de los extraordinarios o subsidia ${ }^{86}$, solicitados por motivos muy concretos.

De una manera esporádica he escrito sobre algunos casos concretos ${ }^{87}$ : sobre un subsidio de 1282 para atender a una situación difícil y sobre otro de 1413 como aportación al inicio del reinado de Fernando I. Pero el asunto exige atención particular. Habría que empezar por reunir y publicar todas las relaciones de casos concretos que pueden ofrecer sorpiesas curiosas, si no otra cosa. Por ejemplo, en el sexenio 1281-1286 el impuesto ordinario de los judíos de la Corona de Aragón ascendía a 160000 sueldos barceloneses anuales mientras que los extraordinarios se elevaron a 985000, que corresponde (985000: 6) a un promedio anual de 165000. O sea, en total 325000 sueldos $^{88}$.

\footnotetext{
${ }^{85} \mathrm{Ni}$ los padrones castellanos publicados (Huete, Aben Nuñes) ni un navarro inédito han sido estudiados, ni en sí ni comparativamente. Pero existen. Esta situación positiva no se da en la Corona de Aragón.

o6 Romano, David, "El reparto del subsidio de 1282 entre las aljamas catalanas, Sefarad. (Madrid-Barcelona), XIII, 1953, 73-86, reimpreso en Romano, David, De historia judía hispánica. (Barcelona, Universitat de Barcelona, 1991), 11-86.

${ }_{87}$ El primer caso está estudiado en el artículo mencionado en la nota anterior. $Y$ el de 1413 en Romano, David, "Los judíos de la Corona de Aragón en la primer mitad del siglo XV", en Actas y Comunicaciones del IV Congreso de Historia de la Corona de Aragón, I. (Palma de Mallorca, Diputación Provincial de Baleares, 1959 [1961]), págs. 239-249, reimpreso en RomANo, David, De historia judía hispánica. (Barcelona, Universitat de Barcelona, 1991), 119-129.

${ }_{88}$ Para apreciar el valor adquisitivo de esas cantidades, diré que en aquel entonces 1 cerdo valía 15 sueldos; 1 gallina o dos conejos, 1 sueldo; 1 docena de huevos, 3 dineros. Esto último, traducido al lenguaje actual ( 25 pta. por docena, valor en Barcelona), significa unos 325 millones de pesetas anuales de valor adquisitivo.
} 


\subsection{Actividades socioeconómicas ${ }^{89}$}

La situación socioeconómica de los judíos era extraordinariamente variada. En realidad lo único que no está documentado son las profesiones que nunca pudieron desempeñar por el hecho mismo de profesar la religión judía: no hubo obispos, ni tampoco militares judíos y a partir de cierto momento no pudieron ocupar cargos de funcionario pues el desempeño de funciones públicas quedó prohibido a raíz de las leyes restrictivas de 1283-1284.

He dedicado algunas monografías ${ }^{90}$ a los funcionarios judíos en el reinado de Pedro el Grande; pero opino que debiera hacerse lo mismo para el de Jaime I, así como recoger los datos anteriores al siglo XIII.

Después de 1283 está documentada la labor de cortesanos, que desempeñaban actividades semipúblicas al servicio del rey y de miembros de la casa real. Por ejemplo, había médicos (físicos y cirujanos), banqueros-prestadores, y aconsejadores - no digo «consejeros»- del rey para asuntos judíos. Muchos de ellos gozaron de exenciones en el vestido, como la de no llevar las llamadas capas redondas y la de no ponerse la señal (la rodela) que obligatoriamente habían de ostentar los judíos, aunque sólo cuando circulaban por el interior de la ciudad.

Un grupo destacado lo formaban los judíos dedicados al comercio y a los negocios. Cuando hablo de comercio me refiero tanto al comercio exterior como al interior y local, pues incluso se conocen contratos para sociedades de carácter mercantil. Hay noticias de mercaderes -mercader es una denominación profesional amplísima- de sedas, de pieles, de especias o simplemente de libros. Además, están atestiguadas las actividades de judíos en la correduría (corredores de oreja, corredores de haberes de Levante, corredores de animales o de libros o de inmuebles). En un terreno distinto, pero directamente relacionado con el dinero, quedan pruebas de su intervención en el arriendo de tributos estatales y de imposiciones municipales. Sin embargo, hay algo que es preciso rechazar

89 Sigo de cerca Romano, David, La Aljama de Judios de Barcelona en el siglo xiv (citado en mi nota 71) y el $\S 4$. de mi inédito Die jüdische Geschichte in der Krone von Aragonien (citado en la nota 10$)$, $\$ 4.2$.

so Véase mi tesis doctoral, aún inédita, Aportaciones al estudio de la organización administrativa de la Corona de Aragón en el siglo xIII (La familia Ravaya y su labor como tesoreros y bailes), premio Menéndez y Pelayo 1952 del Consejo Superior de Investigaciones Científicas; y Judíos al servicio de Pedro el Grande de Aragón (1276-1285). Consejo Superior de Investigaciones Científicas (Institución «Milá y Fontanals») y Universidad de Barcelona (Facultad de Filología). Barcelona 1933, 274 págs. (24 x 17). 
de pleno: la supuesta habilidad comercial de los judíos, un tópico al que luego me referiré especialmente.

La verdad es que la gran mayoría de la población activa judía estaba integrada por artesanos de muy variadas ocupaciones, que formarían una lista larguísima y de difícil clasificación metódica. En el caso de Barcelona está probada la existencia de diversos tipos de contratación laboral, que esquemáticamente serían los siguientes: de aprendizaje, de trabajo a sueldo o a destajo o sin sueldo, y con participación en los beneficios. Desde el punto de vista de los oficios y profesiones una primera clasificación, muy aproximada, podría ser ésta: 1) zapateros, tintoreros y gente dedicada a las artes de la aguja, sea de labores corrientes (tejedores, sastres) o bien más especializadas (botoneras y ojaladoras, al parecer sólo mujeres; cortineros, juboneros, pintores de tejidos de lana, peleteros) o incluso suntuarias (tejedores de seda) ${ }^{91}$; 2) trabajadores de las artes del metal, o de tipo general (herreros) o especializados (ancoreros, cuchilleros, fabricantes de balanzas, linterneros) o plenamente suntuarios (como plateros u orfebres: por ejemplo, los artífices de collares [«paternosters»] de oro o de plata dorada para la reina, o quienes fabricaban piezas de culto cristiano); 3) elaboradores de objetos de materiales diversos, como coraleros y daderos, y especialistas como aquel judío que serró un colmillo de marfil para la reina; o bien torneros (que los documentos no aclaran si trabajaban madera o metales); y, finalmente, 4) otras varias y diversas profesiones, como el servicio doméstico (criados y nodrizas, de judíos se entiende) y los mozos de cuerda, o actividades que exigen conocimientos especiales (boticario, leonero) o el dominio de técnicas poco frecuentes, por ejemplo, los encuadernadores.

A las profesiones citadas deben añadirse rabinos, maestros, notarios y jueces, y algunos curiosos ejemplos de casamenteros ${ }^{92}$. Por añadidura, también conviene recordar las personas dedicadas a oficios de índole cultural como pintores y miniaturistas ${ }^{93}$, mimos y juglares ${ }^{94}$, etc.

\footnotetext{
91 Romano, David, "Los Surí, judíos de Huesca y perleros de la reina de Aragón (1350¿1372?)», Sefarad. (Madrid), XL, 1980 (1982), 255-281, 1 cuadro.

92 Romano, David, "Un casamentero judío (Cardona 1312)"; Sefarad. (Madrid-Barcelona), XXXI, 1971, 103-104, reimpreso en Romano Lavid, De historia judía hispánica. (Barcelona, Universitat de Barcelona, 1991), 145-146. Y también ROMANO, David, «Otros casamenteros judíos (Barcelona-Gerona 1357)», Estudios Históricos y Documentos de los Archivos de Protocolos, V. (= "Miscelánea en honor de Joseph Maria Madurell i Marimon», Barcelona 1977), 299-301.

93 Blasco Martínez, Asunción, "Pintores y orfebres judíos en Zaragoza (siglo xiv)», Aragón en la Edad Media. (Zaragoza), n. $\mathrm{VIII}$ (= Homenaje al profesor emérito Antonio Ubieto Arteta, 1988), 113-131.
}

RIERA I SANS, Jaume, "Cresques Abraham, jueu de Mallorca, mestres de mapamundis i de 


\subsection{Temas concretos}

Para completar esta sucinta exposición de temas amplios susceptibles de ser trabajados, quisiera poner de relieve un par de cuestiones de Iimitado alcance y, sin embargo, dignas de atención.

\subsubsection{La denominación de los judíos}

La primera de esas cuestiones es la de la denominación de los judíos. Aparte de la duplicidad de nombres: uno hebreo y otro hispánico, coexistentes pero en fuentes distintas, la documentación cristiana nos revela que la forma más generalizada de designar o designarse los judíos era la de un prenombre junto con un apellido: el prenombre era un onomástico hebreo presentado en forma más o menos romanizada o bien un prenombre propiamente románico ${ }^{95}$. Asi, por ejemplo, el rabino barcelonés conocido por el acrónimo de Rašbá se llamaba R. Šĕlomó ben Abraham ben Adret y en romance Salomo den Abraham; otro rabino, Aharón haLeví, en los documentos cristianos es citado como Aaron na Clara; Mošé ben Nahmán era Bonastruc ça-Porta, etc.

Pero no todos siguen la misma pauta. $Y$ es que la tradición catalana se inclinaba casi siempre por usar un patronímico, aunque no fueran insólitos los «apellidos», en especial en la zona de Lérida, en la que se vacilaba entre usar el patronímico o bien inclinarse por la costumbre aragonesa e hispánica en general de usar un «apellido» 96.

brúixoles", en L'Atlas català de Cresques Abraham. (Barcelona, Diàfora, 1975), 14-22 -la misma paginación lleva la versión castellana-, demuestra que no era cartógrafo como se ha repetido durante más de un siglo.

${ }_{94}$ Romano, David, «Mims, joglars i ministrers jueus a la Corona d'Aragó (1352-1400)», en Studia in honorem prof. M. de Riquer, 3 (Barcelona, Quaderns Crema, 1988), 133-150.

95 Véase el §1.2.4 (L'onomastique des juifs catalans de l'époque) de Romano, David, Les juifs de Catalogne aux alentours de l'an Mil, Les juifs de Catalogne aux alentours de l'an Mil.En «Catalunya i França meridional a l'entorn de l'any Mil» (Generalitat de Catalunya. Departament de Cultura, Barcelona 1991), 317-331.

${ }^{96}$ Véase Romano, David, Els jueus de Lleida, ponencia en el «l' Col.loqui d'Història dels jueus a la Corona d’Aragós. (Lérida 29-30.1.1989), §1.3, en curso de publicación. 
A partir de 1391 surgen varias denominaciones (en hebreo, en latín, en romance) ${ }^{97}$ aplicadas a los conversos. Habría que ahondar en la historia de esos términos (fecha de aparición, etimología, tiempo y lugar de uso, coexistencia de denominaciones, listas de dobles nombres, etc.). En la Corona de Aragón la que predomina es la de neófito.

Han llegado hasta nosotros al menos tres listas de judeoconversos, que indican el viejo nombre judío y el nuevo nombre que tomaron al convertirse. Corresponden a las ciudades de Barcelona, Palma de Mallorca y Valencia ${ }^{98}$, es decir, las tres de la Corona de Aragón (mientras que no conozco ninguna de las demás naciones hispánicas). A estas listas debieran añadirse los datos aislados aportados por la documentación editada y, mejor aún, habría que completarlas con una investigación que recogiera incluso informaciones procedentes de testamentos de cristianos (tanto si dicen como si no dicen que el testador es un neófito), en los que puedan hallarse alusiones del tipo: "dejo a mi hermano Abraham...", de denominación inequívocamente judía. Uno de los aspectos que pueden considerarse sería el de la creación de cofradías de conversos, quizás transformación o adecuación a nuevas circunstancias de anteriores cofradías judías ${ }^{99}$. Incidentalmente diré que hay que pensar en el posible valor demográfico de esa información.

97 La mayoría de ellas figuran en el artículo de CARRETE PARRONDO, Carlos, «Los judíos de Castilla en la Baja Edad Media», en España. Al-Andalus. Sefarad: Síntesis y nuevas perspectivas. (Salamanca, Universidad de Salamanca, 1988), págs. 144-145. Echo en falta dos vocablos: chuleta y neófito.

Véase FarinelLI, Arturo, Marrano (Storia di un vituperio). Olschki (Biblioteca dell' «Archivum Romanicum», serie Lingüística vol. 10).-Genève 1925-, X + 78 págs. $(23,5 \times 16)$.

98 Singerman, The Jews in Spain and Portugal: A Bibliography (citado en mi nota 41), $\mathrm{n}$. os 38410 y $815=713$, para Barcelona y Palma de Mallorca respectivamente: convendría revisar los originales, si todavía subsisten. La lista de Valencia fue publicada, sin referencia archivística, por GARcía, Angelina, $E$ Is Vives: una família de jueus valencians (Eliseu Climent editor, València 1987), págs. 215-217, que puede completarse con los nombres que aparecen en la pág. 218.

Para Gerona véase la lista confeccionada por RIER A I SANS, Jaume: «Els avalots del 1391 a Girona», en Jornades d'Història dels jueus a Catalunya. Girona abril 1987 (Girona, Ajuntament, 1990), págs. 158-159.

99 Madurell Marimón, José M. a , "La cofradía de la Santa Trinidad, de los conversos de Barcelona», Sefarad. (Madrid-Barcelona), XVIII, 19578, 60-82, y BLASco MARTíneZ, Asunción, "Instituciones sociorreligiosas de los judíos de Zaragoza (siglos $x \mid v-x V$ ). Sinagogas, cofradías, hospitales", Sefarad. (Madrid), XLIX, 1989, 227-236 y L, 1990, 3-46 y 265-288. En el V Congreso Internacional "Encuentro de las Tres Culturas» ("Magia y mística en Toledo"), Toledo 11-14 enero 1988, el llorado Leopoldo Piles Ros presentó una comunicación con el título La cofradía de San Cristóbal de judios conversos valencianos. 
¿Es posible "hoy en día» conocer el origen judío de una persona? Se trata de una pregunta que me dirigen con cierta frecuencia en Barcelona. Mi respuesta suele ser que la única posibilidad consiste en retroceder documentalmente, circunstancia imposible a cinco centenarios de distancia, pues el converso casi siempre buscó una denominación nueva y muy diferente, para despistar: lo demuestra inequívocamente la lectura de los nombres cristianos que figuran en las listas mencionadas. Todo me hace pensar en la búsqueda de apellidos de la Alemania nazi. Con ello se relaciona la cuestión de las familias chuetas, esclerotizadas en 15 nombres, «los quince apellidos»; pero «ni son todos los que están, ni están todos los que son/eran", porque judaizar no quiere decir ser de origen judío.

\section{CONTRA TÓPICOS Y ERRORES ANTIJUDIOOS}

\subsection{Prolegómenos}

Sin perjuicio de que en un futuro próximo trate extensamente de los tópicos sobre los judíos o, sin vacilar, de tópicos antijudíos, creo oportuno referirme aquí a algunos temas que pueden orientar 0 , al menos, evitar la desorientación del investigador.

\subsection{Los judios y el dinero: judíos ricos, judíos pobres}

Una cuestión previa está directamente relacionada con la documentación: en cualquiera época, incluso en la actual, son más conocidos los hechos que guardan relación con el dinero por la sencillísima razón de que tales actos producen o exigen una formalización escrita. Dicho con otras palabras, eso explica que suele repetirse ad nauseam que los judíos sólo se interesaban por lo económico, o se interesaban preferentemente por lo económico. Eso explica pero no justifica, entre otros motivos porque una investigación apurada de los quehaceres cristianos es más que probable que diera resultados semejantes.

Pero el tópico existe y subsiste. Ahora no es el momento adecuado para deshacerlo o rebatirlo. Pero hay algo que es preciso rechazar de pleno: la supuesta habilidad comercial de los judíos: no todos eran comerciantes ni prestadores ${ }^{100}$. Además, no todos los judíos son ricos, ni

\footnotetext{
100 Véase lo que dije en Romano, David, «Prestadores judíos en los estados hispánicos
} 
todos eran o fueron ricos. Aparte de otras varias demostraciones, hay un hecho elocuente: documentos medievales mencionan explícitamente no sólo judíos pobres sino incluso judíos miserables ${ }^{101}$. Por añadidura, únicamente la existencia de tales pobres permiten explicar la existencia de cofradías sociobenéficas, según ha demostrado Asunción Blasco ${ }^{102}$ para el caso de Zaragoza.

\subsection{Préstamo, crédito, usura ${ }^{103}$}

El préstamo merece una mención especial, empezando por decir una cosa y es que incluso la nomenclatura es objeto de partidismo, pues refleja la mentalidad del historiador que habla de él. Crédito es la palabra fina; usura es el término peyorativo; préstamo parece aséptico y positivista. Por añadidura, la problemática es muy compleja y yo destacaría un hecho, uno sólo: jamás, en ningún caso, en ningún documento aparece la palabra prestamista ${ }^{104}$. Por eso hablo siempre de prestador, que me parece un vocablo sin connotaciones envilecedoras.

La sociedad cristiana medieval atacó el préstamo y limitó la usura (interés). Según el derecho canónico un cristiano no puede prestar dinero a otro cristiano - no son raros los ejemplos de préstamos de cristianos a cristianos ${ }^{105}$ _; en el derecho judio la situación es similar: un judío no

medievales", Estudios Mirandeses (Miranda de Ebro), n. ${ }^{\circ}$ III, 1988, 117-126, reimpreso en RoMano, David, De historia judia hispánica. (Barcelona, Universitat de Barcelona, 1991), 421-430.

${ }^{101}$ Camarena Mahiques, José, Colección de documentos para la historia de Gandía y su comarca (Gandía 1959), pág. 47, «juheus miserables». También hay cristianos miserables (págs. $36,40,46)$.

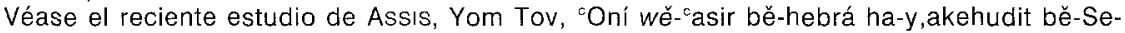
farade ha-yam-tikonit [Pobre y rico en la sociedad judía de la Sefarad mediterránea], $\mathrm{Pe}^{\circ} a m i m$ (Yěrrusaláyim), núm. 46-47 (5751/1990-91), 115-138.

102 BlasCo MARTínez, Asunción, "Instituciones sociorreligiosas de los judíos de Zaragoza (siglos XIV-XV). "Sinagogas, cofradías, hospitales", Sefarad. (Madrid), XLIX, 1989, 227-236 y L, $1990,3-46$ y $265-288$.

103 Traté de este tema en mi conferencia El crédito judío, pronunciada en el ciclo «Dinero, banca y crédito en la Edad Media», de la XVIII Semana Internacional de Estudios Medievales. (Barcelona 26.6.1990). En apéndice publico el guión que repartí entonces.

En general puede verse el libro de SHATZMILLER, Joseph, Shyllock reconsidered. Jews, Moneylending, and Medieval Society. University of California, Bekerley etc. VIII +255 págs. $(21,5$ $\times 14,5$ ).

104 Estas palabras son copia de lo dicho en el $\S 2.3 .1$ (Consideraciones económicas, A). El porcentaje de los préstamos) de mi ponencia Rasgos de la minoria judía en la Corona de Aragón, presentada en el congreso celebrado en Ribadavia (que he citado en la nota 1).

t05 Así, por ejemplo, en 1284 los templarios de Aragón y Cataluña prestaron al infante Alfonso (el futuro Alfonso el Liberal) 10000 sueldos jaqueses "sub usuris". 
puede prestar a otro judío. De ahí que en la Corona de Aragón (igual que en los demás estados hispánicos) se intentara confinar al judío en el préstamo, a cristianos, claro. Es un tema sobre el que he publicado un breve estudio ${ }^{106}$ señalando las características (psicológicas y físicas) de la cuestión. Pero únicamente quiero señalar unos breves datos: después del Concilio IV de Letrán (1215) que prohibía las usuras "excesivas" -pongo de relieve este «excesivas»-, en la Corona de Aragón, al igual que en el reino de Navarra, el máximo del interés legal quedó fijado en el 20 por 100 mientras que en la Corona de Castilla era el 33,3 por 100 (el 25 por 100 durante un breve período).

\subsection{La dedicación a la agricultura ${ }^{107}$}

Las ocupaciones a las que solían dedicarse los judíos eran aquellas que permitían volver a empezar en caso de alejamiento, marginación, destierro, todo lo que se basaba en materia prima transportable, es decir, la artesanía, la medicina, las finanzas. Por consiguiente, había un manifiesto despego de la agricultura.

De buenas a primeras debe decirse que rarísima vez se citan judíos desempeñando actividades agrícolas ${ }^{108}$. En el artículo citado tras el título de este párrafo, he hacho unas cuantas afirmaciones en forma de propuesta de trabajo, resumible en tres puntos, a saber:

1. Está demostrado que los judíos poseían tierras y huertos, viñas y olivares, en general pequeños, adquiridos por compra, por herencia, por donación y quizás como resultado de impago de un préstamo.

2. Parece que el cultivo agrícola se hacía en pequeños terrenos, y que nunca fue/era una ocupación principal sino subsidiaria. Las pocas zonas grandes propiedad de judíos estaban dedicadas a la ganadería.

3. No hay absolutamente ninguna prueba de hábitat rural judío, y se ha demostrado que las huellas de la toponimia son falaces.

106 Véase Romano, David, "Prestadores judíos en los estados hispánicos medievales», Estudios Mirandeses (Miranda de Ebro), VIII (1988), 117-126, reimpreso en Romano David, De historia judia hispánica. (Barcelona, Universitat de Barcelona, 1991), 421-430.

107 Romano, David, «Los judíos y el campo en los estados hispánicos», en Proceedings of the Tenth World Congress of Jewish Studies, division B volume 11: "The History of the Jewish People» (Jerusalem 1990), 135-142.6 Este trabajo ha vuelto a publicarse en la revista Sefarad, con las correspondientes notas y con el nuevo título de «Sefarad" «Judíos hispánicos y mundo rural», -Sefarad (Madrid) LI (1991), 353-367.

${ }_{108}$ Los pocos casos que conozco están recogidos en el $\$ 2.2$ del trabajo que he citado en la nota anterior. 
Insisto - creo que es el error más frecuente repetido-- en que poseer no significa forzosamente cultivar ni habitar en el terreno que se posee.

Añado ahora un breve excursus sobre el vino consumido por judíos. A menudo se ha dicho que los judíos cultivaban viñas a fin de disponer de vino propio. Consta que había tabernas en las que se expendía vino kašer, llamado en romance «vi jueusc» 0 "vino judiego» 0 "vino judienco" ${ }^{109}$. Los especialistas saben bien que eso no es cierto, pues las condiciones para que un vino sea kašer no se refieren especialmente al cultivo ${ }^{110}$, sino a la fabricación, en especial evitar mezclarlo con agua, añadir cal, tal como explicó en su día Asunción Blasco ${ }^{111}$.

\subsection{La facilidad de lenguas ${ }^{112}$}

Hay que negar rotundamente el supuesto don innato de lenguas de los judíos. El plurilingüismo deriva de las circunstancias de la vida: se conoce el hebreo por razones religiosas (como ocurría con el latín para los cristianos: en la Edad Media y hasta hace poco) ${ }^{113} \mathrm{y}$, además, las lenguas de los países en que se ha vivido.

Ante todo, es preciso distinguir entre lenguas habladas y lenguas escritas. Los judíos (de entonces, de hoy, de siempre) hablaban una lengua (normalmente una sola lengua) mientras que algunos escribían una o dos. Hablaban la lengua del estado en que residían, aunque escribían en hebreo y a veces también en la lengua del país, pero con un detalle característico: la escribian con caracteres hebraicos.

En la Corona de Aragón hablaban el romance local: el aragonés en el reino de Aragón y el catalán en los demás estados. En el estado actual de la investigación no hay pruebas de la existencia ni del judeoaragonés ni del judeocatalán, y parece más que fundada la sospecha de que esos posibles dialectos jamás existieron.

106 Es falso lo que dije en ROMANO, David, «Figurantes judíos en representaciones sacras (Villarreal, siglos XIV y XV)», Sefarad. (Madrid-Barcelona), XXIX, 1969, 75-76: el hecho de que no bebieran vino judiego es prueba indudable de que los figurantes no eran judíos.

110 Para la kašrut de la carne tampoco es necesario criar los animales, si bien deben tomarse ciertas medidas precautorias

111 Blasco Martínez, Asunción, "La producción y comercialización del vino» entre los judíos de Zaragoza (siglo xiv)», Anuario de Estudios Medievales (Barcelona), 19, 1989, 405-449.

112 Sigo muy de cerca lo que escribí al hablar de los aspectos diferenciales de los judíos de la Corona de Aragón con otros judios hispánicos, en el $\$ 2.1 .3$, de mi inédito Rasgos de la minoría judía en la Corona de Aragón, citada en la nota 1.

113 En la actualidad, los judios nacidos en Barcelona suelen ser monolingües (aparte de que estudien el inglés u otras lenguas). 
Es oportuno parar mientes en la existencia de judíos bilingües, en especial los que sabían el árabe y una lengua romance, que a veces se ganaban la vida haciendo de trujamanes ${ }^{114}$.

\subsection{La «raza» judía}

De la cuestión de la inexistencia de una «raza» judía he hablado más de una vez ${ }^{115}$. Insisto en que los restos humanos del cementerio de Barcelona demuestran a las claras que los judíos no se distinguían físicamente de los cristianos. No cabe hablar ni de raza ni de etnia judía, ni de características raciales o étnicas.

Tengo por evidente que profesar el judaísmo es cuestión de pensamiento y de sentimientos, o sea, de ideas espirituales, pero nunca en ningún caso ser judío se fundamenta en poseer determinados rasgos físicos. Que luego se mezclen ambos conceptos es cosa muy distinta. Y una prueba, sin duda no parcial, es que nunca ningún proceso inquisitorial habla de eso, sino de creencias, en todo caso de ritos y costumbres que pueden ser materiales pero cuya causa u origen es sin duda alguna espiritual $^{116}$.

\section{SUGERENCIA Y PROPUESTA FINAL ${ }^{117}$}

Como conclusión, final, quiero exponer algunas ideas de carácter general.

\footnotetext{
114 Romano, David, «Judios escribanos y trujamanes de árabe en la Corona de Aragón (reinados de Jaime I a Jaime II), Sefarad. (Madrid), XXXVIII, 1978 (1980), 71-105, reimpreso en Romano, David, De historia judía hispánica: (Barcelona, Universitat de Barcelona, 1991), 239. 273.

Un caso concreto puede verse en Romano, David, "Un texto en aljamía hebraicoárabe (Elche 1314)", Sefarad. (Madrid-Barcelona), XXIX, 1969, 313-318, reimpreso en Romano, David, De historia judía hispánica. (Barcelona, Universitat de Barcelona, 1991), 137-142.

115 Romano, David, Característiques dels jueus en relació amb els cristians en els estats hispànics (citado en mi nota 49), $\S 1.1$, luego traducido, adaptándolo, en mi ponencia Rasgos de la minoria judía en la Corona de Aragón (citada en mi nota 1), $\$ 1.1 .1$ titulado: «Raza» y religión.

${ }_{116}$ Un ejemplo de estas ideas está desarrollado en mi estudio Creencias y prácticas religiosas de los judios de Valencia (1461-1492). Propuestas metodológicas a base de documentos inquisitoriales, mencionado en la nota 46.

117 Repito, casi palabra por palabra, lo que he dicho recientemente en Sevilla, en mi ponencia Judios hispánicos: coexistencia, tolerancia, marginación (1391-1492: de los alborotos a la expulsión). (Sevilla 25.11-30.11.1991), §5.
} 
Un primer grupo de consideraciones se refiere a la exclusión, a ser posible definitiva, de vocablos de uso impropio, entre los cuales señalaría ghetto (realidad inexistente en la Península Ibérica medieval, ni siquiera a raíz de las ordenanzas de 1412); pogrom (impropiamente usada en lugar de «alboroto/s)»; español (que aplicado a la situación medieval debe ser «hispánico»), etc.

Por otra parte, me atrevería a sugerir que este congreso sugiriera a la Real Academia Española la inclusión de algunas palabras nuevas, que se usan cada vez más y que se han utilizado profusamente en este congreso. De ellas doy una primera definición, a todas luces provisional.

Una sería «hispanojudío», naturalmente sin guión, tal como señala el Esbozo (\$1.8.8. i). Sin duda no es tan sonora ni bonita como andalusí que fue introducida en el Diccionario en fecha relativamente reciente ${ }^{118}$. Pero hispanojudío es palabra que recoge fielmente el valor de los dos elementos que la integran, y que podría definirse como "Judío habitante de un país hispánico".

Otra sería «judeoconverso», sin guión, forma que cada vez se oye más, y que debe contribuir a la definitiva eliminación de judeo-converso (con guión) o de circunloquios como converso judío, judío convertido, etc. Yo propondría, también provisionalmente, esta definición: Converso hispánico procedente del judaísmo, muy abundante después de los alborotos antijudíos de 1391 y sobre todo después de la expulsión de 1492.

Una tercera sería "antijudaísmo», definible como «Actitud contraria a lo judío o los judíos (antes llamada antisemitismo) ». De acuerdo con ello, debiera introducirse el adjetivo «antijudío/a», que designaría al «enemigo de los judíos». Simultáneamente, convendría retocar la definición de «antisemitismo", explicando el porqué de su origen.

Universidad de Barcelona, diciembre de 1991.

${ }_{118}$ No figuraba en la $19^{a}$ edición (de 1970) pero fue incluida en la $20^{a}$ (de 1984). 